\title{
EDITORIAL 3
}

\section{La apropiación social del conocimiento como base para la clasificación de las Instituciones de Educación Superior colombianas}

\author{
Adalberto Campo-Arias ${ }^{1}$ (D), Mirith Vásquez-Munive² (D), Guillermo A. Ceballos-Ospino ${ }^{3}$
}

as Instituciones de Educación Superior (IES) colombianas están permanentemente sometidas a -esquemas de clasificación que le otorgan mayor o menor visibilidad en el ámbito académico. Esto genera grandes expectativas y por ello la reciente publicación de la clasificación de la IES colombianas, basado en apropiación social del conocimiento (ASC) ${ }^{1}$, es controversial. Las clasificaciones, como cualquier estrategia que pretende establecer un orden no suelen ser completamente objetivas y se pueden configurar como un dispositivo ideológico y político que promueven la estigmatización y exclusión ${ }^{2,3}$.

La jerarquización tiene consecuencias inmediatas. Las IES mejores posicionadas tienen mayores posibilidades de recibir más recursos financieros de entidades oficiales y privadas. Lo anterior no sería significativo sino se repitiera el hecho que en esos primeros puestos en la clasificación son ocupados por las mismas instituciones, así se perpetúa que incrementan la brecha entre las más y las menos favorecidas ${ }^{2}$. La contraparte, aquellas IES ubicadas en los puestos menos honrosos, esgrime una serie de razones sólidamente argumentadas en las limitaciones del método de evaluación o un conjunto de objeciones que muchos observadores toman como disculpas, excusas o simples pretextos ${ }^{4}$.

La clasificación incluyó un total de 253 IES de las 263 registradas en el país, 89 oficiales y 164 privadas y de éstas, 122 universidades y 131 IES de otro carácter (instituciones tecnológicas, técnica-profesionales o instituciones universitarias sin ser universidades formales), 73 acreditadas y 180 no acreditadas. El índice ASC se calculó basado en cuatro mediciones de la producción y actividades científicas de las IES: participación de la ciudadanía en ciencia, tecnología e innovación, estrategias pedagógicas para el fomento de la ciencia, tecnología e innovación, comunicación social del conocimiento y circulación del conocimiento especializado. Posteriormente, se ordenaron y agruparon en quintiles (Q) ${ }^{1}$.

El índice más alto lo obtuvo la Universidad Nacional de Colombia (ASC 5.151,58; Q1) y el más bajo la Escuela Logística (ASC 1,18; Q5); el segundo lugar lo ocupó la Universidad de Antioquia (ASC 4343; Q3) y el tercero, la Universidad de los Andes (ASC 2646,5; Q3). En los primeros 30 puestos se ubicaron ocho universidades no acreditadas por encima de varias acreditadas ${ }^{1}$.

1. Universidad del Magdalena. Santa Marta, Colombia. Correo: acampoa@unimagdalena.edu.co - https://orcid.org/0000-0003-2201-7404

2.Universidad del Magdalena.Santa Marta,Colombia.Correo:mvasquez@unimagdalena.edu.co-https://orcid.org/0000-0003-2462-4910

3. Universidad del Magdalena. Santa Marta, Colombia. Correo: guillermoceballos@gmail.com - https://orcid.org/0000-0002-1568-7058 
En relación con la Universidad del Magdalena obtuvo el trigésimo octavo lugar (ASC 830,98; acreditada), inferior a otras universidades oficiales del Caribe colombiano, Universidad de la Guajira (puesto 10, ASC 1.605,24, no acreditada), Universidad de Cartagena (puesto 18, ASC 1.314,92; acreditada), Universidad del Atlántico (puesto 20, ASC 1243,7; no acreditada), y Universidad Popular del Cesar, sede Valledupar (puesto 25, ASC 1.072,49; no acreditada). Todas estas universidades del Caribe están en $\mathrm{Q}^{1}$.

Para destacar de estos hallazgos, el mejor desempeño de algunas IES no acreditadas frente a otras acreditadas. En forma jocosa, se puede decir que la acreditación en alta calidad de la IES es de invención algo más reciente que el papel o la imprenta ${ }^{5}$ o como dice el adagio popular "el papel lo aguanta todo"6.

Se puede teorizar que el índice ASC bajó como resultado del número reducido de docentes dedicados a la investigación. Y más allá, la arraigada costumbre de no publicar los hallazgos de la pocas investigaciones que se realizan; no obstante, la tendencia creciente de formación en maestrías y doctorados de los profesores de la IES; esto muestra que ello no garantiza investigación y producción científica, ya sea por las limitadas fuentes de financiación, las horas asignadas para las actividades propias de la ASC o las competencias adquiridas en investigación, $\mathrm{o}$ sea, que las maestrías y doctorados no se reflejan siempre en $\mathrm{ASC}^{7}$.

Por otra parte, el alto número de IES con ASC en Q5 puede ser el resultado de una producción y divulgación científica asimétrica, es decir, que el creciente aumento, por ejemplo, de la producción nacional que se ha observado en publicaciones científicas está en manos de las IES que reciben más recursos ${ }^{8,9}$. Es evidente que la disponibilidad de recursos para investigación incrementa la ASC y se forma un espiral de desigualdad en que las mejor calificadas acceden a más recursos y las peor calificadas cada vez a menos fuentes de financiación. Este fenómeno que confirma la exclusión sistemática de las IES con bajo índice en ASC, con lo que se puede esperar la ampliación de la brecha en futuras mediciones ${ }^{2,3}$.

Otros observadores con una visión más optimista afirmarían que estas IES que muestran desempeño deficiente se debe a que son universidades "profesionalizantes" o que omiten, por distintos motivos, el registro de los componentes de ASC en las fuentes consultadas que invisibiliza la producción de esas IES y la difusión entre los grupos interesados en ese conocimiento generado ${ }^{10}$. La ASC es una función ecuménica de las IES que promueve la inclusión social $^{2,11,12}$.

La ASC es un indicador compuesto de la producción científica y la divulgación, está para los actores que pueden hacer el mejor uso de ella, para que el trabajo académico y científico de las IES tengan un mayor impacto social. La Universidad del Magdalena y otras IES del Caribe colombiano deben trabajar más en esta área, no sólo para mejorar en la clasificación, sino también para contribuir en la solución de los problemas sentidos en todos los ámbitos $\mathbf{y}$ sectores de la región, es decir, que las IES debe ser epicentro de producción de conocimiento, siempre en aras que la producción sea contextualizada y, por tanto, válida, en función de la aplicabilidad y del logro de mejoras sociales.

\section{REFERENCIAS BIBLIOGRÁFICAS}


1. Ranking Asc-Sapiens 2018. Clasificación de las mejores IES colombianas según indicadores de apropiación social del conocimiento. Disponible en: http://www.srg.com.co/ascsapiens.

2. Amsler SS, Bolsmann C. University ranking as social exclusion. Br J Sociol Educ. 2012; 33 (2): 283-301.

3. Shin JC, Toutkoushian RK. University rankings. Dordrecht: Springer; 2011; pp. 1-16.

4. Liu NC. The story of academic ranking of world universities. Int High Educ. 2015; (54): 2-3.

5. Viñao A. Por una historia de la cultura escrita: observaciones y reflexiones. Signos. 1996; 3: 41-68.

6. Triadó XM, Aparicio-Chueca P, ElasriEjjaberi A. La evaluación de competencias en la Educación Superior: el caso de un máster universitario. Reire. 2013; 6 (1): 34-52.

7. Acevedo M, González O, Zamudio L, Abello R,
Camacho J, Gutiérrez M, et al. Un análisis de la transferencia y apropiación del conocimiento en la investigación de Universidades Colombianas. Investigación \& Desarrollo. 2005; 13(1): 128-57

8. Rosselli D. Latin American biomedical publications: the case of Colombia in Medline. Med Educ. 1998; 32 (3): 274-7.

9. Rincón CJ, Lasalvia P, Rosselli D. Ascenso de las publicaciones biomédicas colombianas (carta al editor). Rev Colomb Psiquiatr. 2016; 45 (4): 270.

10. Barrio C. La apropiación social de la ciencia: nuevas formas. Rev Iberoam Cienc Tecnol Soc. 2008; 4(10): 213-25.

11. Fog L. Comunicación de la ciencia e inclusión social. Quark. 2004: (32): 36-41.

12. Osorio J. Formación integral para la apropiación social del conocimiento. Cultur Cuid Enferm. 2010; 7(1): 53-69. 